\title{
The effect of soaking and urea treatments on the voluntary intake of wheat straw by sheep
}

\section{A M Shirif ${ }^{1,2}$, A S Chaudhry ${ }^{2}$, A Younger ${ }^{2}$}

${ }^{1}$ Department of Physiology, Biochemistry and Nutrition, Faculty of Veterinary Medicine. Al-Fateh University, Tripoli Libya, Libyan Arab Jamahiriya, ${ }^{2}$ School of Agriculture, Food and Rural Development, Newcastle University. UK, NE1 7RU, Newcastle Upon Tyne, United Kingdom

Email: sharifam2001@yahoo.co.uk

Introduction It is recognised that advanced maturity in forage like cereal straws was associated with high contents of detergent fibres, lignin and detergent insoluble $\mathrm{N}$ which can reduce the utilisation of these straws by ruminants. While urea treatments have been known to improve the chemical composition and hence utilisation of straws for ruminants, the extent of such improvements depended upon the amount of urea, method of its application and the type of a straw. This study tested the effect of treating wheat straw with different amounts of water (soaking) alone and with different urea levels on voluntary intake in wether sheep.

Materials and methods Nine bales of approximately $300 \mathrm{~kg}$ of wheat straw were chopped (10-15cm), and distributed manually into 18 polyester silo bags that were individually placed inside the galvanized mesh rings. A replicate $2 \times 3$ factorial design was used to apply different urea and water levels to prepare three treated straw bags as replicates per treatment as follows. Water representing 2 soaking ratios $(15: 1$ and $0.50: 1)$ and 3 urea solutions $(0,2.5$ and $5 \%)$ were sprayed onto these straws in bags which were compressed to exclude air, sealed and left outdoors for ten weeks. An animal trial was conducted to compare the voluntary intake of these 6 straws by using 6 similar groups with 6 individual housed wethers per group over 6 weeks. The wethers were offered ad-libtum the above mentioned straws after their mixing in small bathes daily with $3 \%$ molasses for the first two weeks as an adaptation period, and then for another 6 weeks to observe the straw intake by these wethers. The wethers were also fed $200 \mathrm{~g}$ of a concentrate plus $20 \mathrm{~g}$ of a vitamin-mineral premix per head per day to meet the daily protein and energy requirements of a 40kg adult wether (AFRC, 1993). Straw samples and their refusals and spillages were collected daily and stored in labelled plastic bags at $-20^{\circ} \mathrm{C}$ for each week. These samples were thawed, pooled for each treatment per week, dried, ground and analysed to determine their chemical composition and also to estimate the weekly DM intake of relevant straw per wether. Weekly live-weight (LW) of each wether was also recorded, but these are not reported in this paper. The data were statistically analysed by using the Analysis of Variance in Minitab soft ware to compare the effect of soaking, urea and soaking $\mathrm{x}$ urea on the weekly DM intake of these wethers at $\mathrm{P}<0.05$.

Results Only the main effect of urea and soaking treatments on the mean weekly DM intake per weather are shown in figure 1 and 2 respectively. The graphs give an immediate impression of these treatments.

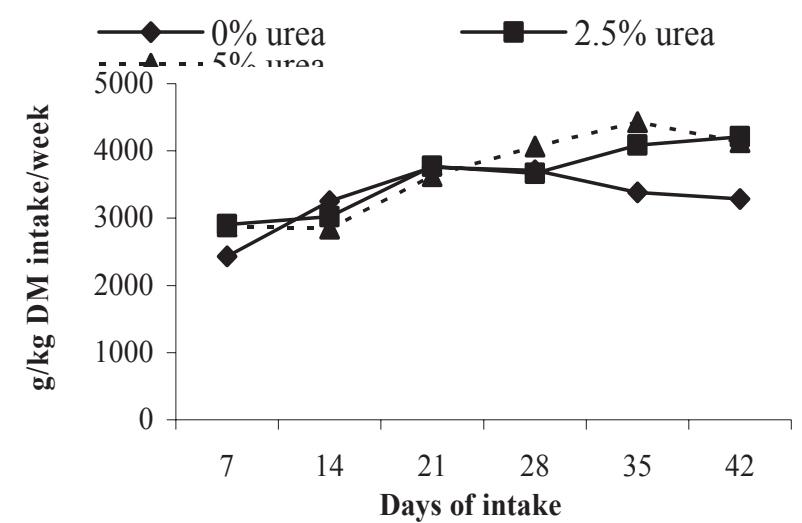

Figure 1 Effect of urea levels on weekly DM intake

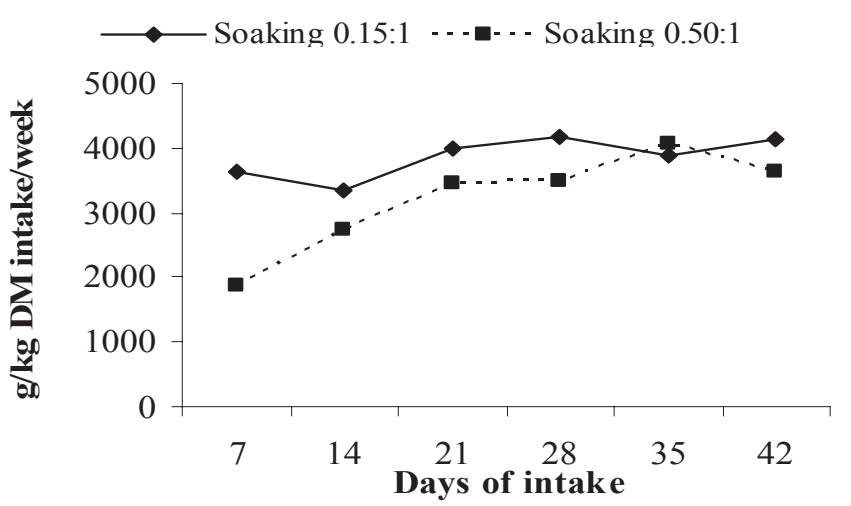

Figure 2 Effect of soaking on weekly DM intake

The DM intake of urea treated wheat straw was significantly increased with the increase in the urea level from 0 to 2.5 or $5 \%$ during the first 7 days and last 14 days of this trial $(\mathrm{P}<0.05)$. However, the extent of this increase in straw intake with urea treatments was less than expected and it was not proportionate to the increase in urea from 2.5 to $5 \%$. The DM intake of straws with low soaking ratio $(0.15: 1)$ was considerably higher than the high soaking ratio straw $(0.50: 1)$ during the first 28 days $(\mathrm{P}<0.05)$ but not in the last 14 days of the trial $(\mathrm{P}>0.05)$. This change in the pattern of straw intake in response to soaking was due to the release of perhaps more soluble nutrients during the rumen fermentation of straw treated at the low soaking ratio. These soluble could have helped accelerate rumen fermentation and the production of volatile fatty acids which might have sent signals to the satiety centre to switch off animal's desire of eating according to the lipostatic theory of feed intake regulation.

Conclusion It appeared that the urea and soaking treatments can improve DM intake of wheat straw by sheep. However the extent of increase in DM intake depended upon the level of urea and soaking treatments which need to be optimised in the future.

\section{Reference}

Agricultural and Food Research Council, 1993. Energy and protein requirements of ruminants. p 24-25. An advisory manual, prepared by the Agricultural and Food Research Council Technical Committee on Responses to Nutrients CAB International, Wallingford, UK. 